\title{
Identification of an effective siRNA target site and functional regulatory elements, within the hepatitis $B$ virus posttranscriptional regulatory element
}

\author{
Nattanan Panjaworayan ${ }^{1}$, Sunchai Payungporn², Yong Poovorawan ${ }^{3}$, Chris M Brown ${ }^{4^{*}}$
}

\begin{abstract}
Background: Infection with hepatitis B virus (HBV) is major public health concern. The limitations of available antiviral drugs require development of novel approaches to inhibit HBV replication. This study was conducted to identify functional elements and new siRNA target sites within the highly conserved regions of the 533 base posttranscriptional regulatory element (PRE) of HBV RNAs.

Results: Computational analysis of the PRE sequence revealed several conserved regulatory elements that are predicted to form local secondary structures some of these within known regulatory regions. A deletion analysis showed that sub-elements of the PRE have different effects on the reporter activity suggesting that the PRE contains multiple regulatory elements. Conserved siRNA targets at nucleotide position 1317-1337 and 1329-1349 were predicted. Although the siRNA at the position 1329-1349 had no effect on the expression of reporter gene, the siRNA target site at the position 1317-1337 was observed to significantly decrease expression of the reporter protein. This siRNA also specifically reduced the level of cccDNA in transiently HBV infected cells.
\end{abstract}

Conclusion: The HBV PRE is likely to contain multiple regulatory elements. A conserved target within this region at 1317-1337 is an effective siRNA target.

\section{Introduction}

Hepatitis B virus (HBV) infection is a major cause of hepatocellular carcinoma and liver cirrhosis worldwide [1]. HBV vaccination can prevent new infections, but effective antiviral drugs are required for the large number of HBV infected people. Current licensed therapies such as interferon- $\alpha$, lamivudine and adefovir dipivoxil have been found to have many limitations. For example, interferon- $\alpha$ is found to have a limited use for a narrow range of patients and is associated with a number of adverse effects whereas a long-term use of lamivudine and adefovir dipivoxil could cause drug-resistant variants of HBV [2]. Novel approaches for inhibiting HBV replication are therefore urgently needed.

\footnotetext{
* Correspondence: chris.brown@otago.ac.nz

${ }^{4}$ Department of Biochemistry, University of Otago, Dunedin, New Zealand Full list of author information is available at the end of the article
}

Currently, RNA interference (RNAi) has been emerged as a potential technique for developing nucleic acidbased gene silencing therapeutics for treatment of viral diseases [3-7]. RNAi is a specific mechanism for downregulation of gene expression. It is evolutionally conserved from plants to mammals. The RNAi process is initiated by short double-stranded RNAs (dsRNAs) that lead to the sequence-specific inhibition of their homologous genes [8]. Previous studies with HBV have shown effective inhibition of HBV replication in mammalian tissue culture and in a mouse model by using synthetic small interfering RNAs (siRNAs) [9-11] and siRNA expression plasmids, which the siRNAs are generated from short hairpin RNA transcripts (shRNAs) and processed into active siRNAs by Dicer in the cytoplasm of cells [12-16].

The HBV genome contains four large overlapping open reading frames that encode for five major proteins namely core, large surface, middle surface, small 
surface and X proteins [17]. Other smaller proteins may be generated by splicing or as regulatory small reading frames [18]. Several sites located on different HBV transcripts were demonstrated to be siRNA target sites $[15,19,20]$. Mostly, these siRNA target sites were predicted along the sequence of HBV genome using bioinformatics programmes, which are based on certain characteristics of ideal siRNAs such as two nucleotides 3 ' overhang, low GC content (36-52\%), base preference at position 3,10,13 and 19, but not by the target mRNA functionality $[19,21,22]$. This approach, although effective, is limited as it does not consider conservation in the genome. Therefore target sites, although initially effective, might be able to be mutated and the virus become resistant.

In this study, we were interested to identify siRNA targets within the HBV post-transcriptional regulatory element (HBV PRE), which is a cis-acting RNA element approximately 500 bases long found in all HBV transcripts. The PRE is a conserved RNA element [23] that has been reported to be involved in the regulation of HBV mRNAs including RNA splicing [24], RNA stability [25] and nuclear export [26-28]. In addition, its nuclear export is affected by myeloid differentiation primary response protein 88 (MyD88) [29]. Several regulatory elements have been identified within the PRE, including a human La binding site [30,31], stem-loop structures, HBV SL $\alpha$ and HBV SL $\beta$ [32], a cis-acting splicing regulatory element (SRE-1) [24], the binding sites (PRE III) of polypyrimidine tract binding protein (PTB) and glyceraldehydes-3-phosphate dehydrogenase (GAPDH) [33-36] (Figure 1A) and binding site of T-cell intracellular antigen 1 (TIA-1) [37], however, the core function of the PRE remains unclear. This study was therefore aimed to investigate potential siRNA target sites within the PRE as well as the core functional elements of the PRE.

\section{Materials and methods}

Bioinformatic analysis of functional elements

The functional elements within the PRE (nucleotides 1151-1684, of Accession number AM282986) were analyzed using results of CDS-Plotcon and Alidot programmes provided by the database HBVRegDB [23]. In brief, a set of 32 completed HBV genomes were analysed by the CDS-Plotcon programme [38] to specifically detect regulatory elements that are present within the coding sequence. They were also analysed using the Alidot programme [39] to determine conserved RNA secondary structures.

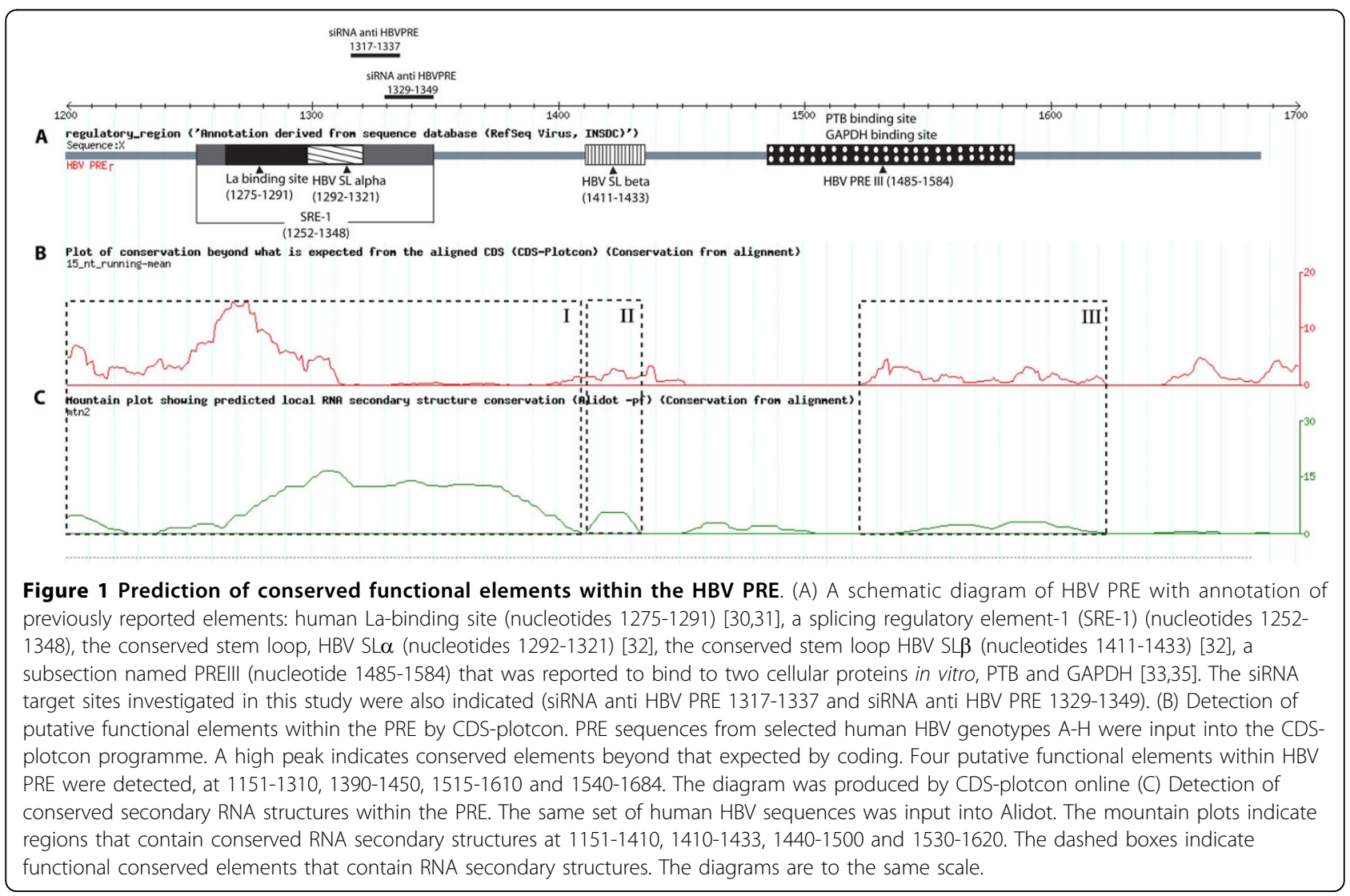




\section{Prediction of siRNA target sites}

The siRNA target sites within the PRE sequence were predicted using siExplorer [40], siDirect [41], and siRNA target designer [42] programmes. Characteristics of desired siRNAs identified by Reynolds et al (2004) [22] were also taken into consideration. Nucleotide blast (blastn) was performed to check specificity of predicted siRNA target sites against human genomic and human transcript databases (Table 1 and additional file 1). The selected sequences were chosen to target PRE positions 1317-1337 and 1329-1349.

\section{Generation of luciferase reporter plasmids}

An intronless reporter vector [pBasic (-IN)] was constructed by removing the chimeric intron of the

Table 1 Overlapping prediction of siRNA target sites found within HBV PRE by different bioinformatics tools

\begin{tabular}{|c|c|c|c|c|c|c|c|c|c|}
\hline \multirow[t]{2}{*}{ Programme } & \multirow[t]{2}{*}{ Position } & \multirow[t]{2}{*}{ Sequence } & \multirow{2}{*}{$\begin{array}{l}\mathrm{GC} \\
(\%)\end{array}$} & \multirow[t]{2}{*}{ Specificity (similarity \%) } & \multicolumn{4}{|c|}{ Position base preference } & \multirow[t]{2}{*}{ Reference } \\
\hline & & & & & $A 3^{*}$ & T10* & Non G13* & A19* & \\
\hline \multirow[t]{3}{*}{ siExplorer } & $\begin{array}{l}1324- \\
1343\end{array}$ & CAUCGGAACUGACAAUUCU & 42.1 & $\begin{array}{l}-73 \% \text { match ARP6 actin-related } \\
\text { protein } 6 \text { homolog transcript } \\
\text { - } 79 \% \text { match chromosome } x \\
\text { genomiccontig }^{2}\end{array}$ & $\mathrm{~T}$ & $\mathrm{~T}$ & C & $\mathrm{T}$ & [40] \\
\hline & $\begin{array}{l}1640- \\
1659\end{array}$ & UGCCCAAGGUCUUACAUAA & 42.1 & $\begin{array}{l}-74 \% \text { match DIX domain containing }^{1} \text { transcript }^{1} \\
-100 \% \text { match chromosome X } \\
\text { genomic contig }\end{array}$ & C & $\mathrm{T}$ & $\mathrm{T}$ & A & \\
\hline & $\begin{array}{l}1641- \\
1660\end{array}$ & GCCCAAGGUCUUACAUAAG & 47.3 & $\begin{array}{l}-73 \% \text { match DIX domain containing } 1 \text { transcript }^{1} \\
-95 \% \text { match chromosome X } \\
\text { genomic contig }\end{array}$ & C & C & A & G & \\
\hline siDirect & $\begin{array}{l}1344- \\
1366\end{array}$ & TCGTCCTCTCGCGGAAATATACA & 52 & 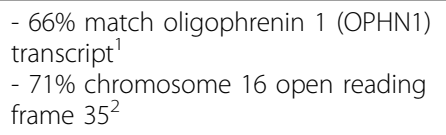 & G & C & G & A & [41] \\
\hline \multirow[t]{2}{*}{$\begin{array}{l}\text { siRNA target } \\
\text { designer }\end{array}$} & $\begin{array}{l}1346- \\
1364\end{array}$ & GTCCTCTCGCGGAAATATA & 47 & $\begin{array}{l}\text { - 73\% match oligophrenin } 1 \text { (OPHN1) } \\
\text { transcript }{ }^{1} \\
-74 \% \text { match hypothetical protein } \\
\text { LOC728975 }\end{array}$ & C & C & A & A & {$[42]$} \\
\hline & $\begin{array}{l}1321- \\
1339\end{array}$ & GCTCATCGGAACTGACAAT & 47 & 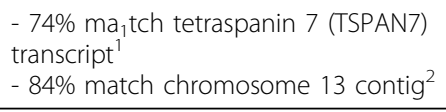 & $\mathrm{T}$ & A & $\mathrm{T}$ & $\mathrm{T}$ & \\
\hline \multirow[t]{6}{*}{$\begin{array}{l}\text { Reynolds } \\
\text { et al (2004) }\end{array}$} & $\begin{array}{l}1317- \\
1337^{*}\end{array}$ & AAAGCTCATCGGAACTGACAA & 42 & $\begin{array}{l}\text { - } 66 \% \text { match tetraspanin } 7 \text { (TSPAN7) } \text { transcript } \\
\text { - } 81 \% \text { match chromosome } 2 \text { genomic } \\
\text { contig }^{2}\end{array}$ & A & C & A & C & [22] \\
\hline & $\begin{array}{l}1318- \\
1338\end{array}$ & AAGCTCATCGGAACTGACAAT & 42 & 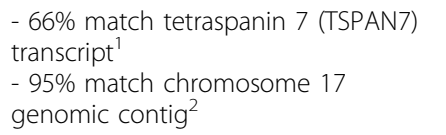 & G & G & A & A & \\
\hline & $\begin{array}{l}1329- \\
1349^{*}\end{array}$ & AACTGACAATTCTGTCGTCCT & 42 & $\begin{array}{l}-76 \% \text { match zinc finger protein } 559 \\
\text { (ZNF559) transcript }{ }^{1} \\
-76 \% \text { match chromosome } 19 \\
\text { genomic contig }\end{array}$ & C & $\mathrm{T}$ & $\mathrm{T}$ & C & \\
\hline & $\begin{array}{l}1336- \\
1356\end{array}$ & AАTTCTGTCGTCCTCTCGCGG & 52 & $\begin{array}{l}\text { - } 71 \% \text { match F-box and leucine-rich } \\
\text { repeat protein } 15 \text { transcript }^{1} \\
-81 \% \text { match chromosome } 20 \\
\text { genomic contig }\end{array}$ & $\mathrm{T}$ & G & C & C & \\
\hline & $\begin{array}{l}1357- \\
1377\end{array}$ & AAATATACATCGTTTCCATGG & 33 & $\begin{array}{l}\text { - } 62 \% \text { match ADAM metallopeptidase } \\
\text { domain } 12 \text { (ADAM12) transcript } \\
\text { - } 76 \% \text { match chromosome } 11 \\
\text { genomic contig }\end{array}$ & A & $\mathrm{T}$ & $\mathrm{T}$ & $\mathrm{T}$ & \\
\hline & $\begin{array}{l}1358- \\
1378\end{array}$ & АATATACATCGTTTCCATGGC & 42 & $\begin{array}{l}\text { - } 67 \% \text { match bactericidal/permeability } \\
\text { increasing protein-like } 2 \text { (BPIL2) } \\
-76 \% \text { match chromosome } 11 \\
\text { genomic contig }\end{array}$ & $\mathrm{T}$ & C & $\mathrm{T}$ & G & \\
\hline
\end{tabular}

Predicted siRNA target sites from siExplorer, siRNA target design and Reynolds et al. (2004) [22] were found to have overlapped regions. Bold indicates the position base preference. ${ }^{\prime \prime \prime}$ indicates the selected siRNA target sites, ${ }^{\prime \prime} \prime$ and ${ }^{2 \prime}$ ' indicate the best matches from the blastn search against human transcript and genomic databases respectively. Details of the blastn matches are in additional file 1. 
pGL3MS2site/Basic reporter construct [43]. To construct a splicing luciferase reporter vector (pSpliceLuc), the parental vector, pGL3MS2site/Basic was modified to place the $l u c+$ gene between the splicing donor (SD) and splicing acceptor (SA) sites. This modification involved two-step cloning. The first cloning involved amplification of the SD (forward: SV40+ 5'-ctgactaatttttttatttatgc-3', reverse: SDR_AflII 5'-gaattccttaagccttaaacctgtcttgtaacc- $3^{\prime}$ ) and then the amplification of the SA sequence (forward: SAF_XhoI 5'-gaattcctcgagagaccaatagaaactgggc- $3^{\prime}$, reverse: SAR_EcoRV $5^{\prime}$-gaattcgatatccctgtggagagaaaggcaaagtg- $3^{\prime}$ ).

\section{Amplification of the deletion series of the PRE}

Three pairs of primers were specifically designed to amplify three sub-sections of the HBV PRE: (i) full length HBV PRE (forward: HBVPRE_1151F 5'-tctagagctagcttgct cggcaacggcctggtctgtg-3', reverse: HBVPRE_1684R 5'gccggcctcgaggacattgctgaga gtccaagagtcc-3'); (ii) HBV PRE 1399-1684 (forward: HBVPRE_1399F 5'-tctagagc tagctggatccttcgcgggacgtcctttg-3', reverse: HBVPRE_1684R 5'gccggcctcgagga cattgctgagagtccaagagtcc- $3^{\prime}$ ) and (iii) HBV PRE 1485-1584 (forward: HBV PRE_1485F 5'-tctagagctagctcgtccccttctccgtct-3', reverse: HBV PRE_1584R 5'gccgg cctcgaggtgcacacggaccggcagat- $\left.3^{\prime}\right)$. The Amplification was performed from a clone containing the complete HBV genome (a gift from M-H Lin, National Taiwan University) using Expand ${ }^{\text {tM }}$ High Fidelity DNA polymerase (Roche). Short fragments of the PRE 1292-1321 and HBV PRE 1411-1433 were created by annealing synthetic oligonucleotides: (i) forward: HBVSL_alpha oligoF 5'-ctag cgttttgctcgcagccggtctggggcaaagcc-3', reverse: HBVSL_alpha oligoR 5'-tcgaggctttgccccagaccggctgcgagcaaaacg-3'; and (ii) forward: HBVSL_beta oligoF 5'-ctagcgggacgtcctttgtttacgtcccc-3', reverse: HBVSL_beta oligoR 5'tcgaggggacgtaaacaaaggacgtcccg-3'.

\section{Generation of siRNA expression plasmids}

Selected siRNA target sites at positions 1317-1337 and 1329-1349 were converted into shRNA template oligonucleotides by adding the loop sequence, the target site's antisense strand and a termination signal for the RNA pol III (Figure 2A). For cloning purposes, overhangs of half restriction enzyme sites for BamHI and HindIII were flanked at the $5^{\prime}$-end and the $3^{\prime}$-end of the template respectively. Sequences of the shRNA templates for targeting HBV PRE 1317-1337 and 1329-1349 were as follows: PRE1317 5'-gatccagctcatcggaactgacaattcaagagattgtcagttccgatgagcttttttggaaa-3'; 5AtPRE1317 5'agcttttccaaaaaaagctcatcggaactgacaatctcttgaattgtcagttccgatgagctg-3'; PRE 1329 5'-gatccgctgacaattctgtcgtcctttcaagagaaggacgacagaattgtcagttttttggaaa-3'; AtPRE1329 5'agcttttccaaaaaactgacaattctgtcgtccttctcttgaaaggacgacagaattgtcagcg- $3^{\prime}$. Then, the two complementary hairpin
siRNA oligonucleotides (each contains $1 \mu \mathrm{g} / \mu \mathrm{L}$ ) were annealed together and ligated with the cut pSilencer 3.0-H1 promoter vector (Ambion).

\section{Western blot analysis}

Cell lysates were separated on 4-12\% Bis-Tris gel (NuPAGE ${ }^{\bullet}$ Novex gel, InvitrogenTM Life Technologies) and electrophoretically transferred onto polyvinylidene difluoride (PVDF) membrane (Hybond-P, Amersham Pharmacia Biotech). Blots were blocked with $5 \%$ of skim milk in TBS-T buffer for $1 \mathrm{~h}$ and subsequently incubated at $4{ }^{\circ} \mathrm{C}$ for overnight with appropriate diluted primary antibodies, anti-Luc (1:500, Roche), anti-GAPDH (1:2,500, Ambion) and anti-PABP (1:10,000, Abcam). Then blot was incubated with diluted horseradish peroxidase-conjugated secondary antibody, goat anti-mouse $(1: 10,000$, BIORAD) at room temperature for $1 \mathrm{~h}$. For chemiluminescent detection, the immuno-blot was applied with the ECL Plus reagents (Amersham Pharmacia Biotech) and exposed to X-ray films (HyperfilmTM, Amersham Bioscience) for 15 $\mathrm{s}-10 \mathrm{~min}$ at room temperature. All exposed films were then processed and qualified by imaging densitometry (Molecular Analyst software).

\section{Mammalian tissue culture and transfection}

$\mathrm{HuH}-7, \mathrm{HepG} 2$ and COS-7 cells were cultured in 75 $\mathrm{cm}^{3}$ sterile tissue culture flasks (Greiner Bio-One) at $37^{\circ}$ $\mathrm{C}$ with $5 \% \mathrm{CO}_{2}$ in DMEM supplemented (Invitrogen) with $10 \%$ heat inactivated FBS (10\% v/v) (Invitrogen) and $1 \% \mathrm{~L}$-glutamine (Invitrogen). Prior to transfection, cells were seeded on 24-well plates (Greiner Bio-One) with a cell density approximately $1 \mathrm{X} 10^{4}$ cells $/ \mathrm{mL}$ and incubated for $24 \mathrm{~h}$. All transfection was performed using FuGENE6 (Roche). The ratio between FuGENE6 $(\mu \mathrm{L})$ and DNA $(\mu \mathrm{g})$ was 3:1. For deletion analysis, $195 \mathrm{ng}$ of the deletion series of HBV PRE reporter plasmids were transiently co-transfected in quadruplicate with $5 \mathrm{ng}$ of the internal control plasmid (phRL-SV40: Promega, a plasmid expressing humanized Renilla luciferase protein). pUC18 was used to top up the total amount of DNA if required. For evaluating effect of siRNA expression plasmids, cells were co-transfected in triplicate with $95 \mathrm{ng}$ pSpliceLuc/fPRE or pBasic (-IN)/fPRE, $5 \mathrm{ng}$ of phRL-SV40 and various amounts $(0 \mathrm{ng}, 300 \mathrm{ng}, 600 \mathrm{ng}$ and $900 \mathrm{ng}$ ) of the siRNA expression plasmids. For studying the siRNA effect of the pShRNA PRE 13171337 on the luciferase protein, cells were transiently cotransfected in triplicate with $45 \mathrm{ng}$ of pSpliceLuc/fPRE or pBasic (-IN)/fPRE, $5 \mathrm{ng}$ of the phRL-SV40 and either $60 \mathrm{ng}$ or $300 \mathrm{ng}$ of the pShRNA PRE 1317-1337 construct. The pSilencer-Negative was used to make up the total of plasmid DNA to $350 \mathrm{ng}$. The pSilencer-GAPDH was also included in the experiment as the positive control for the siRNA effect on the GAPDH protein. 


\section{A. ShRNA template oligonucleotides:}

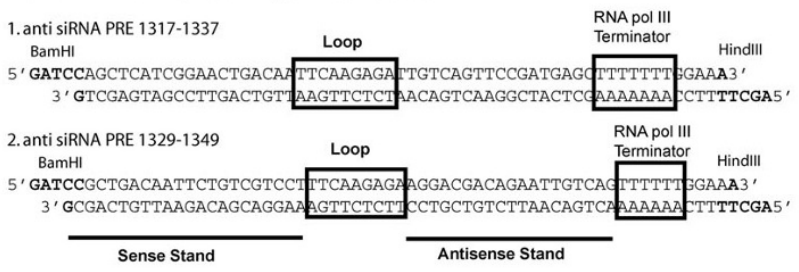

B.
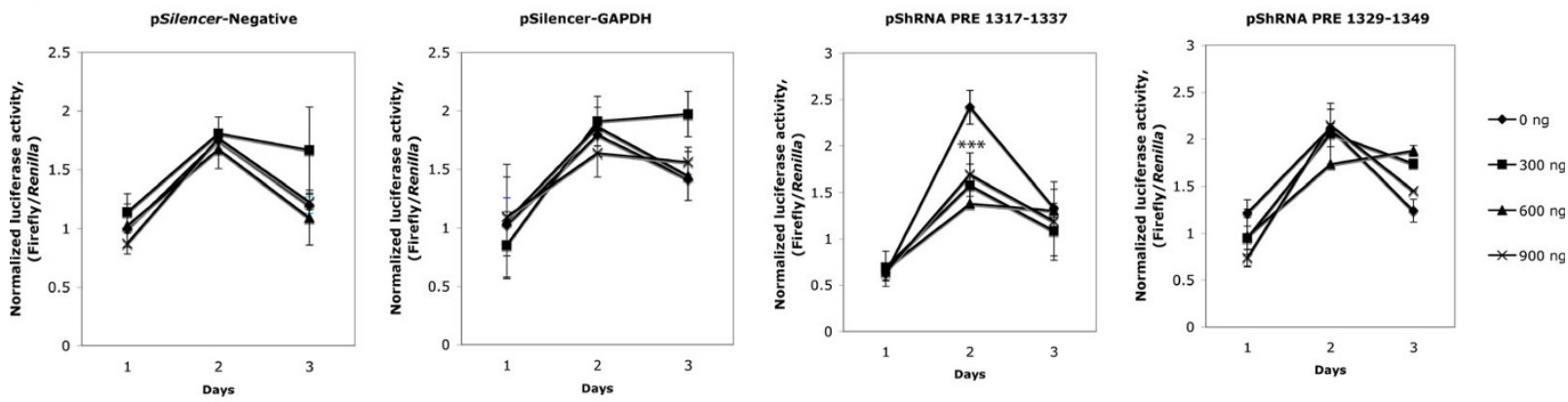

C
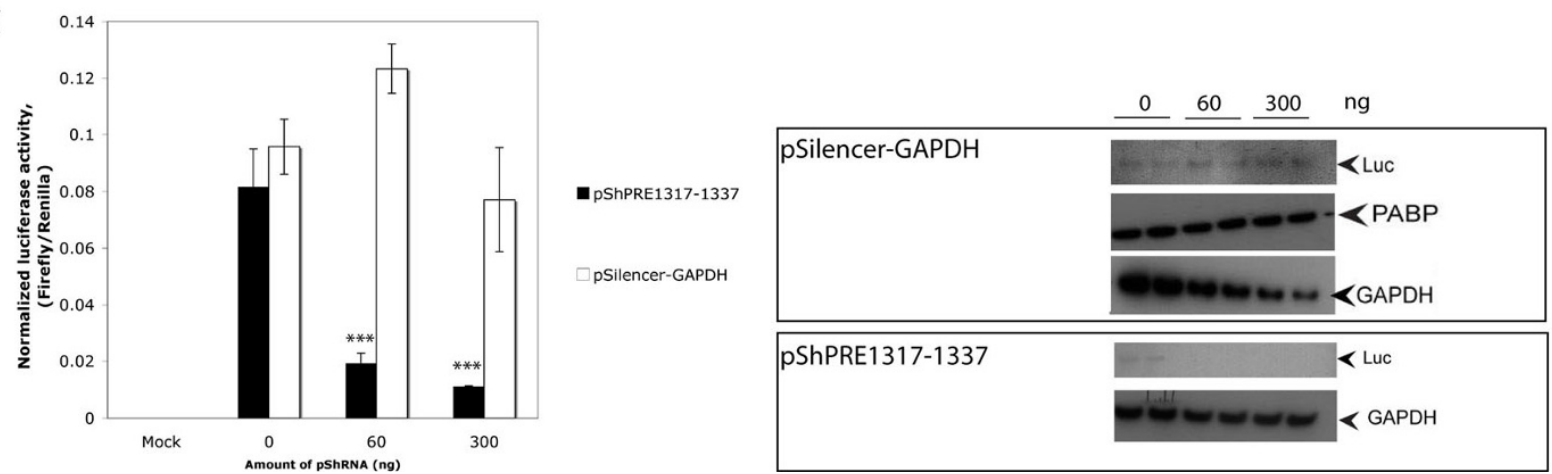

Figure 2 The effect of siRNA expression plasmids on reporter activity. (A) ShRNA template oligonucleotides of siRNA anti PRE 1317-1337 and PRE 1329-1349. (B) The effects of pShRNA plasmids on luciferase activity. The line graphs indicate normalized luciferase activities of transfected COS-7 cells with pSilencer-Negative, pSilencer-GAPDH, pShRNA PRE1317-1337 and pShRNA 1329-1349. COS-7 cells were transfected in triplicate with $95 \mathrm{ng}$ of pLucSplice/fPRE, $5 \mathrm{ng}$ of phRL-SV40 and various amount of pSiRNA expression plasmids as indicated, pUC18 was used to make up the total DNA to $1 \mu \mathrm{g}$. Cells were harvested at day 1 , day 2 and day 3 post-transfection and analyzed for expression of luciferase protein. ${ }^{1 * * * \prime}$ indicates significant differences of normalized luciferase activities compared to $0 \mathrm{ng}$ of siRNA expression plasmid with $\mathrm{p}<0.001$ (by t-test). (C) The effect of pShRNA PRE1317-1337 on the luciferase activity in HuH-7 cells. In this experiment, cells were transiently transfected in triplicate with $45 \mathrm{ng}$ of the pSpliceLuc/fPRE, $5 \mathrm{ng}$ of the phRL-SV40 and different amounts of the pShRNA constructs as indicated. pSilencerNegative was used to make up total DNA plasmid to $350 \mathrm{ng}$. Cells were harvested and analyzed luciferase activity and western blot analysis after $48 \mathrm{~h}$ of incubation. Reporter expression levels are higher from these SV40 promoter containing constructs in COS- 7 cells (B) than in Huh-7 cells (C). The bar graph shows normalized luciferase activity of mean values of three independent experiments; error bars represent standard deviation. ${ }^{* * * \prime}$ indicates significant differences of normalized luciferase activities comparing to the control siRNA expression plasmid (pSilencerGAPDH) with $p<0.001$ (by t-test). Western blot analysis with primary antibodies: anti-GAPDH, anti-firefly luciferase protein (anti-Luc) and antiPoly A binding protein (anti-PABP) and the horseradish peroxidase-conjugated secondary antibody.

\section{Luciferase activity assay}

Forty-eight $\mathrm{h}$ post-transfection, cells were lysed with 100 $\mu \mathrm{L}$ of $1 \times$ passive lysis buffer (Promega). Cell debris and nuclei were removed by centrifugation and the supernatant was collected. The luciferase activity assay was performed as described by Tanguay and Gallie (1996)

\section{Quantitative real time- PCR analysis of HBV cccDNA}

A plasmid expressing covalently closed HBV genome (EMBL:AM282986) was constructed in pGEM-T Easy
Vector (Promega, Madison, WI) through a T-A cloning strategy. Serial 10-fold dilutions of the cccDNA standard plasmid from 10 to $10^{10}$ copies/ $\mu \mathrm{L}$ were detected by real-time PCR assay and used to prepare the standard curve for quantitation of HBV cccDNA. The standard curve of HBV cccDNA was then constructed by plotting the logarithm of the initial plasmid concentration against the threshold cycle $(\mathrm{Ct})$ obtained from each dilution. The standard plasmid DNA for quantitation was included in each run as an external standard. HBV 
cccDNA was amplified and quantified in real-time PCR assay using the primers and probe as described previously [44]. The forward primer was HBV_CCC_F1 (5'actcttggactc cagcaatg- $\left.3^{\prime}\right)$; the reverse primer was HBV_CCC_R1 (5'-ctttatacgggtcaatgtcca-3') and the cccDNA specific probe was FAM-ttcaagcctccaagctgtgccttg-BHQ1. The optimized real-time PCR reaction mixture comprised $1 \mu \mathrm{L}$ of DNA template, 0.75 $\mu \mathrm{M}$ final concentration of each primer, $0.25 \mu \mathrm{L}$ of the probe, $5 \mu \mathrm{L}$ of $2 \times$ Platinum qPCR Super Mix-UDG (Invitrogen, California, USA), additional $2.5 \mathrm{mM} \mathrm{MgCl}_{2}$, and nuclease-free water to a final volume of $10 \mu \mathrm{L}$. The real-time PCR assay was carried out in a Rotor Gene RG-3000 (Corbett Research, Australia) under the following conditions: initial denaturing step at $95^{\circ} \mathrm{C}$ for 10 min, followed by 45 cycles of $95^{\circ} \mathrm{C}$ for $15 \mathrm{~s}$ and $61.5^{\circ} \mathrm{C}$ for $1 \mathrm{~min}$. Then the Rotor-Gene Software Version 6.0 (Corbett Research) was used for data acquisition and analysis of the HBV cccDNA level. The result was indicated in term of relative quantitation by comparative threshold (delta-delta $\mathrm{Ct}$ ) method $\left(2^{-\Delta \Delta \mathrm{Ct}}\right)$. The amount of target gene in the sample, normalized to an endogenous housekeeping gene (reference gene) and relative to the normalized calibrator, is then given by $2-\Delta \Delta \mathrm{Ct}$, where

$$
\Delta \Delta \mathrm{Ct}=\Delta \mathrm{Ct}(\text { sample })-\Delta \mathrm{Ct}(\text { calibrator })
$$

$\Delta \mathrm{Ct}$ (sample) $=\mathrm{Ct}$ (target gene of sample) $-\mathrm{Ct}$ (reference gene of sample)

$\Delta \mathrm{Ct}$ (calibrator) $=\mathrm{Ct}$ (target gene of calibrator) $-\mathrm{Ct}$ (reference gene of calibrator)

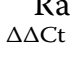

Ratio (folds of difference) of sample: calibrator $=2$

In this study, the reference gene was beta-globin, the target gene was the cccDNA of HBV co-transfected with siRNA, and the calibrator was cells transfected with only the HBV plasmid.

\section{Results and discussion}

The HBV PRE was predicted to contain multiple functional conserved elements

The HBV post-transcriptional regulatory element is highly conserved among the mammalian hepadnaviridae [23]. As the sequence of the PRE also encodes the P protein, the conservation may partly be due to constraints on the encoded protein. This study therefore analyzed functional core elements of the PRE using results generated by the CDS-plotcon programme, which scores conservation beyond what is required for coding [38] as well as using programmes for predicting conserved RNA secondary structure [39]. CDS-plotcon indicated four conserved elements within the functional PRE at nucleotide positions 1151-1310, 1390-1450, 1515-1610 and 1540-
1684 (EMBL: AM282986, Figure 1B). Three of these potential conserved regulatory elements were predicted to form local RNA secondary structures by Alidot (Figure $1 C)$. The results of both programmes therefore suggested three putative functional conserved elements at nucleotide positions 1151-1410, 1411-1433 and 1510-1620 (Dashed boxes, Figure 1).

Notably, the previously identified regulatory elements: the human La binding site [30], SRE-1 [24] and HBV SL alpha [32] are shown to be part of a large secondary RNA structure within the predicted functional element at the position 1151-1410 whereas the reported HBV SL beta [32] and the PRE III [34,35] are part of the identified functional elements at the position 1411-1433 and 1520-1620 respectively (Figure 1). In addition, known regulatory elements at the DNA level are also found to be part of the region identified as the functional elements (high mountain peak) generated by the CDS-plotcon such as the DNA enhancer 1 (nucleotide position 900-1310), the X promoter (nucleotide position 9501310), the DNA primer binding DR1 (nucleotide position 1590-1600) and the DNA enhancer 2 (nucleotide position 1636-1744) $[45,46]$.

Taken together, the results support that the PRE is an important regulatory region that contains multiple functional conserved elements.

\section{HBV PRE 1317-1377 is a novel siRNA target site}

Although several sites in the HBV genome have previously been able to be targeted by siRNA, there is no report of targets within this region of PRE. To predict siRNA target sites, the sequence was analysed using three programmes, siExplorer [40], siDirect [41] and siRNA target designer [42]. In addition, the criteria of ideal siRNAs reported by Reynolds et al (2004) [22] were also taken into consideration. The predicted siRNA target sites were checked for specificity using nucleotide blast (blastn) against human genomic and transcript databases. Predicted siRNA target sequences that had more than $85 \%$ identity to human genomic DNA or transcripts were designated as non-specific siRNA targets and not used. As a result, an overlapping region of predicted siRNA target sites was detected by three different approaches (Table 1). Selected siRNA target sites were chosen to cover this region, at nucleotide position 1317-1337 and 1329-1349 (Figure 1A). These two predicted siRNA sites were found within the identified putative functional PRE element (nucleotide position 1151-1410) and they are part of a large predicted conserved RNA secondary structure (Figure 1). Selected siRNA target sites were converted into shRNA template oligonucleotides (Figure 2A) and ligated with the cut siRNA expression vector (pSilencer 3.0-H1, Ambion). The generated siRNA expression plasmids 
were designated as pShRNA PRE 1317-1337 and pShRNA PRE 1329-1349. Subsequently, various amounts (0 ng, 60ng, $300 \mathrm{ng}, 600 \mathrm{ng}$ and $900 \mathrm{ng}$ ) of the generated siRNA expression plasmids were transiently cotransfected in triplicate with $95 \mathrm{ng}$ of luciferase reporter vector (pSpliceLuc/fPRE or pBasic (-IN)/fPRE) and $5 \mathrm{ng}$ of Renilla expression plasmid (phRL-SV40) using FuGENE6. The experiment also included the positive control shRNA plasmid (pSilencer-GAPDH, Ambion), which targets the human GAPDH mRNA and the negative control plasmid (pSilencer-Negative, Ambion) a scambled sequence that is not found in the human genome. Cells were harvested at different time points (1 day, 2 days, 3 days post-transfection).

The result shows that the pShRNA PRE 1317-1337 could specifically and significantly reduce the level of luciferase activity at the day 2-time point (Figure 2B, p $<0.001$ ) even with a low amount (60 ng) of the siRNA expression plasmid (Figure 2C). In contrast, the presence of pShRNA PRE 1329-1349 in different amounts showed no effect on luciferase expression at any time point (Figure 2B) although it was selected by similar criteria and position to the effective siRNA target site 1317-1337 (Table 1 and Figure 1). Therefore, the results suggest that specific properties of siRNA target sites are more significant than others for effective targeting. The level of pBasic (-IN)/fPRE was also significantly reduced by this siRNA ( $60 \mathrm{ng}$, by $43 \%$ and $300 \mathrm{ng}$, by $79 \%$ ).
Anti-HBV PRE 1317-1337 specifically reduced the level of ccCDNA in transiently HBV infected cells

This experiment was carried out to evaluate whether the anti-HBV PRE 1317-1377 could also inhibit HBV replication in infected cells. This was done by measuring the level of HBV covalently closed circular DNA (cccDNA) in HepG2 cells that were transiently co-transfected with $30 \mathrm{ng}$ of a HBV clone that expresses HBV and with 0 ng, $100 \mathrm{ng}$ or $600 \mathrm{ng}$ of the pShRNA PRE 1317-1377. Forty eight $h$ post-transfection, cells were harvested to analyze the level of cccDNA using quantitative real time PCR. The results indicated that the plasmid expressing siRNA anti-HBV PRE 1317-1377 significantly reduced the level of cccDNA in transiently infected cells (Figure $3, \mathrm{p}<0.001)$.

Previous reports showed that new formation of cccDNA in transfected cells was directly controlled by the expression of $\mathrm{HBV}$ transcripts $[47,48]$. As this siRNA target site (HBV PRE 1317-1337) is present in all HBV transcripts, it is possible that any or all HBV transcripts were reduced by the siRNA, resulting in the reduction of level of cccDNA.

\section{Sub-sections of the PRE have different effects on the reporter gene activity}

To investigate the functional core elements of the PRE, a deletion series of the PRE was designed based on these predictions (CDS-plotcon and Alidot) and

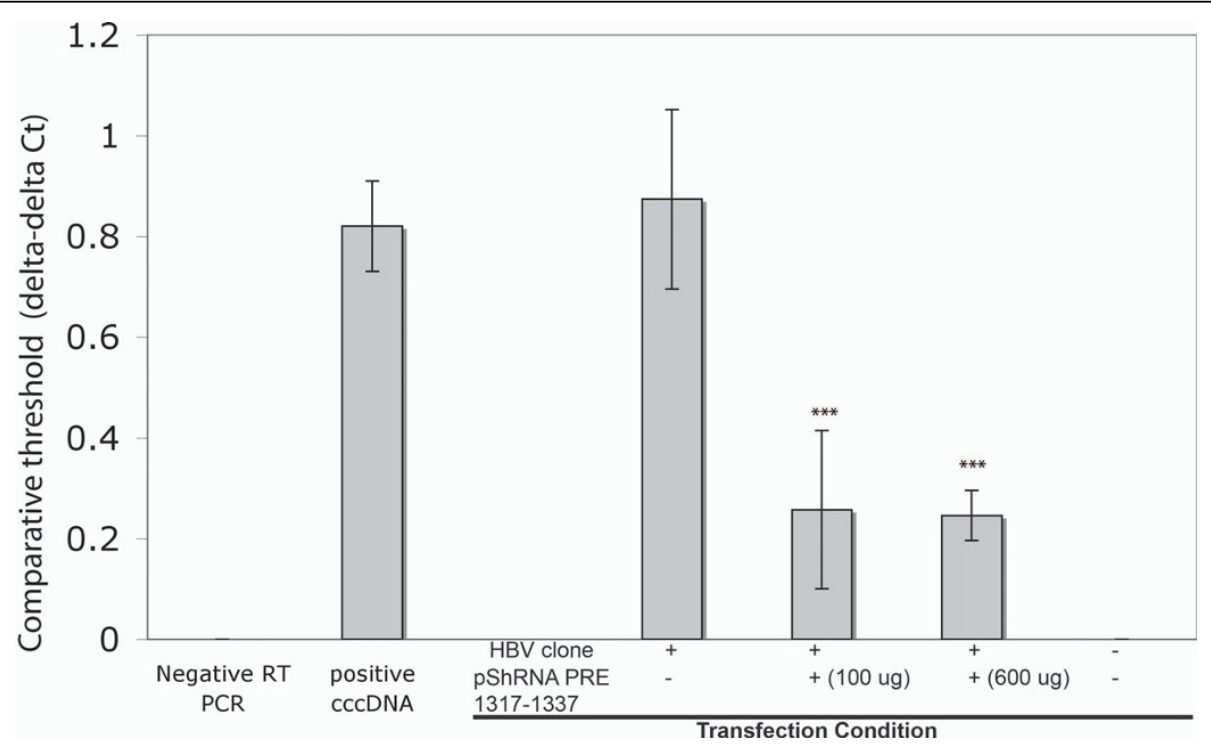

Figure 3 The effect of pShRNA PRE 1317-1337 on the expression of cccDNA. Bar graphs indicate mean values of thresholds of three independent experiments. In this study, HepG2 cells were transiently transfected in triplicate with 45 ng of the pSpliceLuc/fPRE, 5 ng of the phRL-SV40 and different amounts of the pShRNA constructs as indicated. pSilencer-Negative was used to make up total DNA plasmid to 350 ng. Cells were harvested and analyzed for luciferase activity and western blot analysis after $48 \mathrm{~h}$ of incubation. ${ }^{* * * \prime}$ indicates significant differences of comparative threshold comparing to the controls (positive cccDNA and cells without transfection of pShPRE 1317-1337) with $p<0.001$ (by ttest). 
previous reports on PRE regulatory elements, HBV SL alpha (nucleotide position 1291-1321), PRE III (nucleotide position 1485-1584) (Figure 1). Each PRE subsection was then specifically generated by PCR and then inserted into two different luciferase $(l u c+)$ reporter constructs digested at NheI and XhoI sites: (i) the splicing $l u c+$ reporter construct (pSpliceLuc), and (ii) the intronless luciferase reporter construct [pBasic (-IN)] (Figure 4A). Notably, the pSpliceLuc construct has the $l u c+$ gene within an intron, thus it could be used to study whether the PRE could enhance the unspliced luc + gene expression. On the other hand, the pBasic (-IN) reporter construct was designed to study functional nuclear export of PRE by imitating the natural context of the intronless HBV $S$ transcript where PRE is located the 3' UTR of the gene. Subsequently, a deletion series of the PRE reporter plasmids were transiently co-transfected in quadruplicate with the phRL-SV40 vector in HuH-7 and COS-7 cells.

The full length (fPRE) significantly enhanced unspliced $l u c+$ gene expression in both $\mathrm{HuH}-7$ (Figure 4B, p < 0.001) and COS-7 cells (data not shown). This result suggests that the fPRE either inhibit splicing or enhance nuclear export, or both. Surprisingly, the PRE sub-section 1399-1684 significantly inhibited unspliced $l u c+$ gene expression $(\mathrm{p}<0.001)$ whereas PRE sub-section 1292-1321 (HBV SL alpha), HBV PRE 1411-1433 (HBV SL beta) and HBV PRE 1485-1584 (PRE III) did not

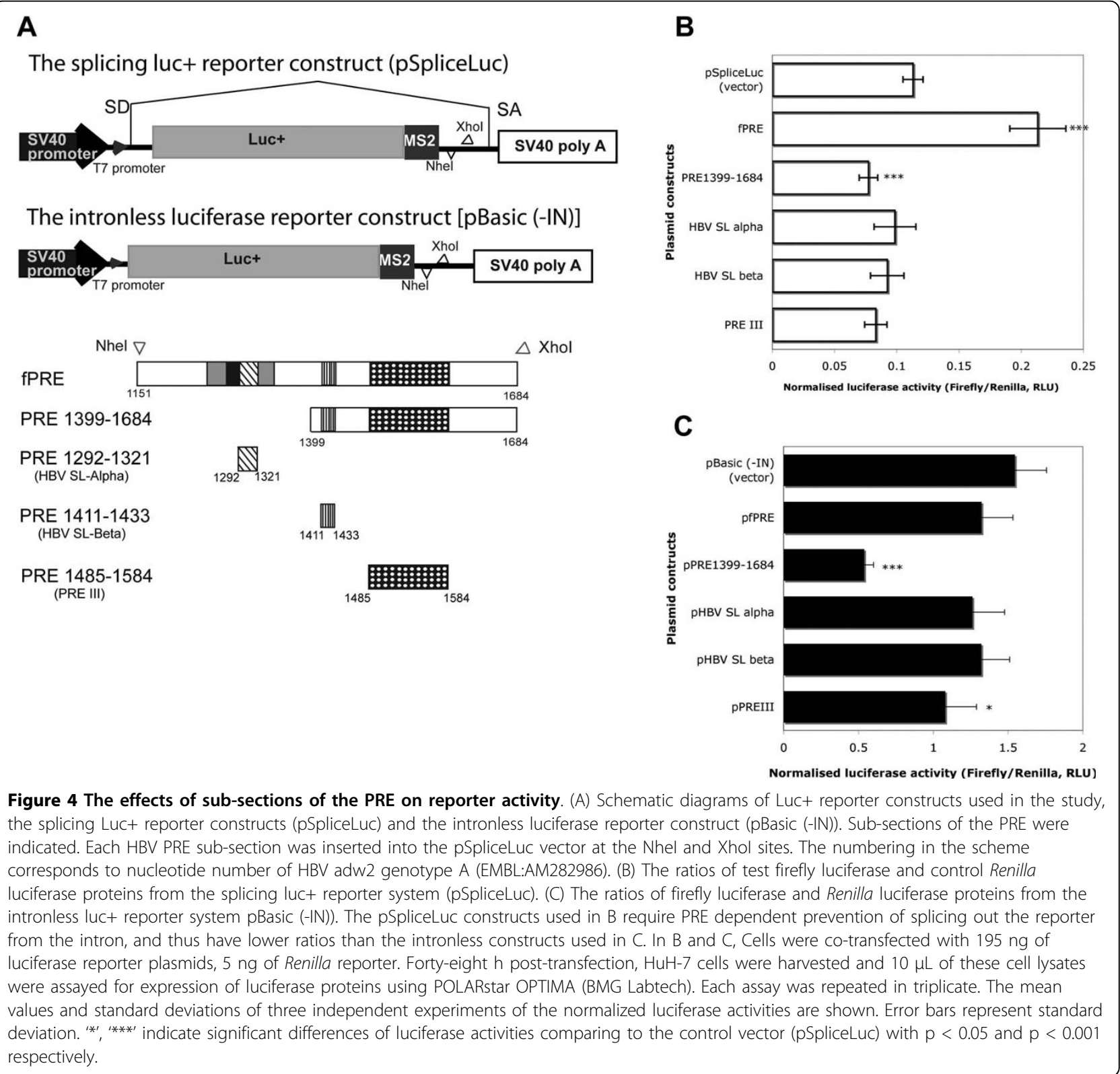


individually enhance the expression of unspliced luc+ (Figure 4B). This result was consistent with previous published results, using the cat reporter system (pDM138), this construct has a design similar to the unspliced $l u c+$ reporter construct used in this study. The previous report indicated that duplication of HBV SL beta and HBV SL alpha was required to enhance the level of CAT activity in the cat reporter system (pDM138) [26]. Indeed, six copies of HBV PRE III were reported to increase the CAT activity (pDM138 reporter system) in the same level as the full-length the PRE [49].

On the other hand, the results from the intronless luc + construct showed that none of the PRE sub-sections including the PPRE were able to enhance the expression of the intronless $l u c+$ gene. Interestingly, the PRE subsection 1399-1684 also significantly inhibited the intronless $l u c+$ gene whereas PRE alpha, PRE beta had no effect on the expression of intronless $l u c+$ gene (Figure 4C). Previously using northern blot analysis and primer extension, the PRE has been shown to significantly increase cytoplasmic export of the HBV S RNA $[27,50]$. It has also been reported to function in the context of heterologous genes by enhancing expression of intronless transcripts of $\beta$-globin and c- myc [27,50-52]. In this study, the PRE failed to increase activity of the intronless Luc+ protein (Figure 4C). Therefore, experimental results from this study provide evidence suggesting that the ability of the PRE to enhance expression of intronless transcripts is not applicable to all intronless genes. It is possible that the PRE may not have an effect on the highly expressed gene $l u c+$ whereas it did on poorly expressed reporters (e.g. cat). Therefore, the results of PRE deletion analysis from the intronless luct system might not be able to conclusively evaluate the identified functional elements. Subsequent studies should be conducted to test the function of these PRE elements in a natural context using pgRNA ( $\mathrm{C}$ and $\mathrm{P}$ proteins) or surface (S) protein.

Interestingly, the PRE sub-section 1399-1684 significantly reduced luciferase activity (Figure $4 \mathrm{~B}, \mathrm{p}<0.001$ ). This result was also observed in the intronless $l u c+$ reporter system (Figure 4C, p < 0.001). The result may suggest either that the PRE sub-section 1399-1684 contains a novel inhibitory element or that the PRE subsection 1151-1398 is an important element for the function of the PRE. Taken together, the PRE appears to contain multiple weak regulatory elements, but some aspects regarding the function of the PRE are still unclear.

\section{Conclusion}

In summary, we showed that the HBV PRE contains the effective siRNA target site (nucleotide position 1317-1337) that when targeted with shRNA could reduce the level of cccDNA in transiently transfected cells. However, more experiments are required to optimize the duration and efficiency of the siRNA effect. The computational and deletion analysis suggested that the HBV PRE is likely to contain several relatively weak regulatory elements that vary in conservation. These elements may have different functions during the HBV lifecycle.

\section{Additional material}

Additional file 1: Blastn matches for potential siRNAs targeting the PRE region of $\mathrm{HBV}$. The file contains blastn results of potential siRNA target sites. The results indicate Score search, E-value and a list of matched sequences and sequence alignments.

\section{Acknowledgements}

We would like to express our deep appreciation to the Clinical Virology Centre, Faculty of Medicine, Chulalongkorn University. NP is funded by Research Grant for New Scholar (co-funded by TRF and CHE: MRG5380104), The Kasetsart University Research and Development Institute Grant (45.53) and The PRF Grant (Faculty of Science, Kasetsart University). Part of this work was supported by a NZ Health Research Council Grant (05/195) to Warren Tate, Elizabeth Poole and CMB.

\section{Author details}

${ }^{1}$ Department of Biochemistry, Faculty of Science, Kasetsart University, Bangkok, Thailand. '2Department of Biochemistry, Faculty of Medicine, Chulalongkorn University, Bangkok, Thailand. ${ }^{3}$ Center of Excellence in Clinical Virology, Department of Pediatrics, Faculty of Medicine, Chulalongkorn University, Bangkok, Thailand. ${ }^{4}$ Department of Biochemistry, University of Otago, Dunedin, New Zealand.

\section{Authors' contributions}

NP carried out: the bioinformatic analysis of functional elements and prediction of siRNA targets, plasmids' constructions, Western blot analysis, luciferase activity assay and drafted the manuscript. SP carried out the quantitative real-time-PCR analysis and participated in the manuscript. YP participated in the design of the study and analysis of the quantitative realtime-PCR study. CMB conceived of the study, and participated in its design and coordination. All authors read and approved the final manuscript.

\section{Competing interests}

The authors declare that they have no competing interests.

Received: 30 June 2010 Accepted: 8 September 2010

Published: 8 September 2010

\section{References}

1. Kao JH, Chen DS: Global control of hepatitis B virus infection. Lancet Infect Dis 2002, 2:395-403.

2. Tillmann HL: Antiviral therapy and resistance with hepatitis $B$ virus infection. World J Gastroenterol 2007, 13:125-140.

3. Anesti AM, Peeters PJ, Royaux I, Coffin RS: Efficient delivery of RNA Interference to peripheral neurons in vivo using herpes simplex virus. Nucleic Acids Res 2008, 36:e86.

4. Habayeb MS, Ekstrom JO, Hultmark D: Nora virus persistent infections are not affected by the RNAi machinery. PLoS One 2009, 4:e5731.

5. Kim SM, Lee KN, Park JY, Ko YJ, Joo YS, Kim HS, Park JH: Therapeutic application of RNA interference against foot-and-mouth disease virus in vitro and in vivo. Antiviral Res 2008, 80:178-184.

6. Liu YP, von Eije KJ, Schopman NC, Westerink JT, Brake OT, Haasnoot J, Berkhout B: Combinatorial RNAi Against HIV-1 Using Extended Short Hairpin RNAs. Mol Ther 2009, 1710:1712-1723. 
7. Pacca CC, Severino AA, Mondini A, Rahal P, D'Avila S G, Cordeiro JA, Nogueira MC, Bronzoni RV, Nogueira ML: RNA interference inhibits yellow fever virus replication in vitro and in vivo. Virus Genes 2009, 38:224-231.

8. Elbashir SM, Lendeckel W, Tuschl T: RNA interference is mediated by 21and 22-nucleotide RNAs. Genes Dev 2001, 15:188-200.

9. Li GQ, GU HX, Li D, Xu WZ: Inhibition of Hepatitis B virus cccDNA replication by siRNA. Biochem Biophys Res Commun 2007, 355:404-408.

10. Giladi H, Ketzinel-Gilad M, Rivkin L, Felig Y, Nussbaum O, Galun E: Small interfering RNA inhibits hepatitis B virus replication in mice. Mol Ther 2003, 8:769-776.

11. Ying C, De Clercq E, Neyts J: Selective inhibition of hepatitis B virus replication by RNA interference. Biochem Biophys Res Commun 2003, 309:482-484

12. Starkey $\mathrm{J}$, Chiari EF, Isom HC: Hepatitis B virus (HBV)-specific short hairpin RNA is capable of reducing the formation of HBV covalently closed circular (CCC) DNA but has no effect on established CCC DNA in vitro. J Gen Virol 2009, 90:115-126.

13. Kayhan H, Karatayli E, Turkyilmaz AR, Sahin F, Yurdaydin C, Bozdayi AM: Inhibition of hepatitis B virus replication by shRNAs in stably HBV expressed HEPG2 2.2.15 cell lines. Arch Virol 2007, 152:871-879.

14. Ying RS, Zhu C, Fan XG, Li N, Tian XF, Liu HB, Zhang BX: Hepatitis B virus is inhibited by RNA interference in cell culture and in mice. Antiviral Res 2007, 73:24-30.

15. McCaffrey AP, Nakai H, Pandey K, Huang Z, Salazar FH, Xu H, Wieland SF, Marion $\mathrm{PL}$, Kay MA: Inhibition of hepatitis $B$ virus in mice by RNA interference. Nat Biotechnol 2003, 21:639-644.

16. Peng J, Zhao $Y$, Mai J, Pang WK, Wei $X$, Zhang $P, X u$ Y: Inhibition of hepatitis $B$ virus replication by various RNAi constructs and their pharmacodynamic properties. J Gen Virol 2005, 86:3227-3234.

17. Seeger C, Mason WS: Hepatitis B virus biology. Microbiol Mol Biol Rev 2000, 64:51-68.

18. Chen A, Kao YF, Brown CM: Translation of the first upstream ORF in the hepatitis $B$ virus pregenomic RNA modulates translation at the core and polymerase initiation codons. Nucleic Acids Res 2005, 33:1169-1181.

19. Arbuthnot $P$, Carmona $S$, Ely $A$ : Exploiting the RNA interference pathway to counter hepatitis B virus replication. Liver Int 2005, 25:9-15.

20. Wu KL, Zhang X, Zhang J, Yang Y, Mu YX, Liu M, Lu L, Li Y, Zhu Y, Wu J: Inhibition of Hepatitis $B$ virus gene expression by single and dual small interfering RNA treatment. Virus Res 2005, 112:100-107.

21. Chen $Y$, Cheng G, Mahato RI: RNAi for treating hepatitis B viral infection. Pharm Res 2008, 25:72-86.

22. Reynolds A, Leake D, Boese Q, Scaringe S, Marshall WS, Khvorova A: Rational siRNA design for RNA interference. Nat Biotechnol 2004, 22:326-330.

23. Panjaworayan N, Roessner SK, Firth AE, Brown CM: HBVRegDB: annotation, comparison, detection and visualization of regulatory elements in hepatitis B virus sequences. Virol J 2007, 4:136.

24. Heise T, Sommer G, Reumann K, Meyer I, Will H, Schaal H: The hepatitis B virus PRE contains a splicing regulatory element. Nucleic Acids Res 2006, 34:353-363.

25. Ehlers I, Horke S, Reumann K, Rang A, Grosse F, Will H, Heise T: Functional characterization of the interaction between human La and hepatitis $B$ virus RNA. J Biol Chem 2004, 279:43437-43447.

26. Donello JE, Beeche AA, Smith GJ, Lucero GR, Hope TJ: The hepatitis B virus posttranscriptional regulatory element is composed of two subelements. J Virol 1996, 70:4345-4351.

27. Huang J, Liang TJ: A novel hepatitis B virus (HBV) genetic element with Rev response element-like properties that is essential for expression of HBV gene products. Mol Cell Biol 1993, 13:7476-7486.

28. Huang ZM, Yen TS: Hepatitis B virus RNA element that facilitates accumulation of surface gene transcripts in the cytoplasm. J Virol 1994, 68:3193-3199.

29. Li J, Lin S, Chen Q, Peng L, Zhai J, Liu Y, Yuan Z: Inhibition of hepatitis B virus replication by MyD88 involves accelerated degradation of pregenomic RNA and nuclear retention of pre-S/S RNAs. J Virol 2010, 84:6387-6399

30. Heise T, Guidotti LG, Chisari FV: La autoantigen specifically recognizes a predicted stem-loop in hepatitis B virus RNA. J Virol 1999, 73:5767-5776.

31. Horke S, Reumann K, Rang A, Heise T: Molecular characterization of the human La protein.hepatitis B virus RNA.B interaction in vitro. J Biol Chem 2002, 277:34949-34958
32. Smith GJ, Donello JE, Luck R, Steger G, Hope TJ: The hepatitis B virus posttranscriptional regulatory element contains two conserved RNA stemloops which are required for function. Nucleic Acids Res 1998, 26:4818-4827.

33. Zang WQ, Yen TS: Distinct export pathway utilized by the hepatitis $B$ virus posttranscriptional regulatory element. Virology 1999, 259:299-304.

34. Zang WQ, Fieno AM, Grant RA, Yen TS: Identification of glyceraldehyde-3phosphate dehydrogenase as a cellular protein that binds to the hepatitis B virus posttranscriptional regulatory element. Virology 1998 248:46-52.

35. Zang WQ, Li B, Huang PY, Lai MM, Yen TS: Role of polypyrimidine tract binding protein in the function of the hepatitis $B$ virus posttranscriptional regulatory element. J Virol 2001, 75:10779-10786.

36. Li Y, Huang T, Zhang X, Wan T, Hu J, Huang A, Tang H: Role of glyceraldehyde-3-phosphate dehydrogenase binding to hepatitis $B$ virus posttranscriptional regulatory element in regulating expression of HBV surface antigen. Arch Virol 2009, 154:519-524.

37. Tang H, Huang Y, Chen J, Yu C, Huang AL: Cellular protein TIA-1 regulates the expression of HBV surface antigen by binding the HBV posttranscriptional regulatory element. Intervirology 2008, 51:203-209.

38. Firth $A E$, Brown $C M$ : Detecting overlapping coding sequences in virus genomes. BMC Bioinformatics 2006, 7:75.

39. Hofacker IL, Fekete M, Stadler PF: Secondary structure prediction for aligned RNA sequences. J Mol Biol 2002, 319:1059-1066.

40. Katoh T, Suzuki T: Specific residues at every third position of siRNA shape its efficient RNAi activity. Nucleic Acids Res 2007, 35:e27.

41. Naito Y, Yamada T, Ui-Tei K, Morishita S, Saigo K: siDirect: highly effective, target-specific siRNA design software for mammalian RNA interference. Nucleic Acids Res 2004, 32:W124-129.

42. Promega: siRNA target designer-version 1.6. 2003 [http://www.promega. com/si RNADesigner/program/].

43. Rackham O, Brown CM: Visualization of RNA-protein interactions in living cells: FMRP and IMP1 interact on mRNAs. Embo J 2004, 23:3346-3355.

44. He ML, Wu J, Chen Y, Lin MC, Lau GK, Kung HF: A new and sensitive method for the quantification of HBV cccDNA by real-time PCR. Biochem Biophys Res Commun 2002, 295:1102-1107.

45. Dejean A, Sonigo P, Wain-Hobson S, Tiollais P: Specific hepatitis B virus integration in hepatocellular carcinoma DNA through a viral 11-basepair direct repeat. Proc Natl Acad Sci USA 1984, 81:5350-5354.

46. Moolla N, Kew M, Arbuthnot P: Regulatory elements of hepatitis B virus transcription. J Viral Hepat 2002, 9:323-331.

47. Kuo TM, Hu CP, Chen YL, Hong MH, Jeng KS, Liang CC, Chen ML, Chang C: HBV replication is significantly reduced by IL-6. J Biomed Sci 2009, 16:41.

48. Chou YC, Jeng KS, Chen ML, Liu HH, Liu TL, Chen YL, Liu YC, Hu CP, Chang $C$ : Evaluation of transcriptional efficiency of hepatitis $B$ virus covalently closed circular DNA by reverse transcription-PCR combined with the restriction enzyme digestion method. J Virol 2005, 79:1813-1823.

49. Huang ZM, Zang WQ, Yen TS: Cellular proteins that bind to the hepatitis B virus posttranscriptional regulatory element. Virology 1996, 217:573-581.

50. Huang ZM, Yen TS: Role of the hepatitis B virus posttranscriptional regulatory element in export of intronless transcripts. Mol Cell Biol 1995, 15:3864-3869.

51. Guang S, Mertz JE: Pre-mRNA processing enhancer (PPE) elements from intronless genes play additional roles in mRNA biogenesis than do ones from intron-containing genes. Nucleic Acids Res 2005, 33:2215-2226.

52. Lu S, Cullen BR: Analysis of the stimulatory effect of splicing on mRNA production and utilization in mammalian cells. Rna 2003, 9:618-630.

\section{doi:10.1186/1743-422X-7-216}

Cite this article as: Panjaworayan et al:: Identification of an effective siRNA target site and functional regulatory elements, within the hepatitis B virus posttranscriptional regulatory element. Virology Journal 2010 7:216. 